\title{
SITUATIONAL LEADERSHIP AND ORGANIZATIONAL BEHAVIOR
}

\author{
Federico de Andreis ${ }^{1}$ \\ Federico Leopardi ${ }^{2}$
}

DOI: https://doi.org/10.31410/LIMEN.2020.223

\begin{abstract}
In the organizations and their management, an important fundamental role is played by the "leadership style", since administrating the working relationships in complex organizations, influences their final results.

The decision-making process, in fact, within the organization is influenced by managerial leadership.

Before going into the analysis of the various models through which we can propose to read the phenomenal complexity of leadership within business management, this research aims to identify what is leadership and also the roles and dimensions within an organization.

The goal of the analysis is to explore the study of leadership styles, from the more formal and authoritarian to the more participative, and to demonstrate the situational leadership approach, which does not presume a unique approach to every situation in order to be successful.
\end{abstract}

Keywords: Leadership, Organizational behaviour, Management.

\section{INTRODUCTION}

$\mathrm{W}$ orking in a team is part of that skillset that students, practitioners, workers and managers should have when it comes to creating value for the company. Group experiences are daily occurrences since human beings are social animals, and those interactions with elements of the same species are normal. Diving more deeply into what our society is nowadays, it is possible to see that teamwork is omnipresent within a company's boundaries. The natural consequence in a team very often is the emersion of a leader and consequently, the success of a team is determined by good leadership.

It is not an easy task neither defining leadership, nor identify the various approach to leadership that it is possible to have. Over the years, academics have tried to study leadership in general and the winning model of the perfect leader, trying to determine the leader's features and the behaviours for the success of the organisation.

\section{METHODOLOGY}

In the organizations' management, a fundamental role is played by the "leadership style", from the most authoritarian to the most participative, since administrating the working relationships in complex organizations, influence their final results. For this reason, the investigation of leadership, its approaches and its consequences cannot disregard a clear definition of organizational dynamics, structurally linked to the mission.

Università Giustino Fortunato, Benevento (I), Italy

University of Groningen, Groningen (NL), Netherlands 
The research approach and the discussion, in order to facilitate understanding of the aforementioned dynamics and dimensions, follows a division by sections of the article in sections one, two... that identify organizational units, almost from a holistic point of view.

Through that methodology, it will be possible to explore the study of leadership styles, from the more formal and authoritarian to the more participative, and to demonstrate the situational leadership approach, which does not presume a unique approach to every situation.

\section{DISCUSSION}

\section{a. The team}

People's working life revolves mostly around the capacity to work in team, and managers are asked to control and understand teams' trends to better use them and achieve higher goals.

In today's world, companies tend more often to include their employees in the decision-making process, asking them to take responsibilities. These responsibilities are then translated into a group or a team.

By definition a group is composed of two or more people that identify themselves in a common identity, interacting using their rules and aiming at a common goal.

Each member of the group has the same goal and cooperates with the others in order to achieve it.

A group can exist only when people in the group recognise the existence of the group itself, hence, the presence of the leader - which will be seen later in the paper - can be made by everyone's agreement on the role of the leader. The mere physical presence in a small space does not make a group as one unless everyone recognise it.

A group can be spontaneously made based on people's interests such as political reasons, religion, ethnicity since the interaction within the members is easier if not imposed from above.

Therefore, in a working team values and opinions shall be shared. Setting a common goal is the main reason for group formation. The words group and team are frequently used interchangeably, although, they do not mean the same thing. A team is a limited number of people who have complementary capabilities, used for a shared goal, aiming objectives that have a similar approach (Spencer, 1993).

Due to internal conflicts between the members, and unstable relationships, many groups may not succeed and will not become teams.

\section{b. Teams typology}

In general, groups can be divided into two macro-categories:

- Primary groups, at the beginning of everyone's life, individuals enter in on group (involuntarily) which is generally family, relatives, the neighbourhood, and the first friendships given by the circumstances. 
- Secondary groups, entering adult life, individuals select in which group they want to belong, and it is then started a rigid and more accurate selection usually basing our preferences on as shared interests or common ideas.

Moreover, groups can be further divided into formal and informal organisations:

- Formal if the organisation was born to perform a specific activity within fixed deadlines (e.g., content creators, marketing campaigns, etc.)

- Informal if it is initially created by a personal need of the individual who connects and group peoples and engaging them for a shared goal.

Before the group is created, various phases are performed (Tuckman, 1965). Five well defined and phases are present (from the model of Tuckman of 1965 one more phase was added in 1977):

- Forming, the orienteering phase. In this phase, the group has not been created yet, but a defined amount of people is taking part in the organisation. Roles, scopes, and goals are defined as a first draft. At this moment members are trying to understand what their roles will be and where they can be in the hierarchy (if one there will be). The first leader is being identified, however, in this phase roles shift very easily.

- Storming, in this phase politics and argumentation of the leader are on a testing field. This is a turning point, within a group multiple sub-groups could take place in this phase which decrees whether the group will still be alive for the following phases or not.

- Norming, in this phase the cohesion is pursued. This phase is characterised by internal confrontation, this is a phase in which members are now mature and able to disengage any conflict, if not able to manage this phase again the group can hardly make it to the next one.

- Performing, in this phase, the group has a solid structure. Members are now part of a well- established group. Everyone has a specific role to perform and individuals are well synchronised. In this phase it is important to make wise use of feedback, in fact the group can only improve its performances if constructive comments are delivered.

\section{c. Group size}

To create a group, it is important to select the appropriate number of group members. A work team, project team or task force are usually composed of a small number of people. Generally, four people create six relationships within the members of the team. In this way, cognitive processes are pursued, such as group think.

The maximum number of members is not well-defined; however, a cap of ten people is reasonable to think to be the maximum acceptable. A higher number would create unbalanced situations and too many people to express their thoughts and ideas.

On the one hand, people can be a resource but on the other hand, people are so precious that treating them shallowly would be degrading.

\section{d. Roles in a group}

The roles and functions performed by the members are part of the organisation structure. By functions, it is intended the activities that are performed in the group, whilst roles are expectative that members build and develop while communicating with each other. 
The decision-making process within the organisation is the main role of the management, which through proper leadership - authoritarian, or laissez-faire -handles work relationships within the organisation and influencing the result driven by the proper leadership style.

Therefore, the leadership within a group or organisation has the main purpose of serving the needs of a single person in order to reach the shared goal.

Members are a resource and using properly the resources the organisation can aim at increasing and improving the richness delivered to the stakeholders - via moving the resources, better allocating and changing them - so that the organisation can have a successful future. Moreover, the creating of value becomes the main goal that through the adequate management and inspiration of the team it is possible to achieve, if the management declares the strategies and the objective to reach, the leader decides how and in which way to achieve it respecting the boundaries set by the management.

\section{e. Conflicts}

Within a group, it is understandable that conflicts arise, and conflict resolution is surely another skill that team members and leaders must have in their skillset.

As above-mentioned providing feedback can be the key to success for a team. This can be translated into conflict resolution, which besides avoiding useless waste of resources, it can be constructive or disruptive.

The disruptive nature of a conflict can be seen when the efficacy of the team is affected by competitive behaviours within the group boundaries, which would divert the focus of the team from the main goal.

The constructive nature of the conflict takes place when members are aware that conflicts are naturally part of the group and for this reason, these moments can be seen and an enriching situation for all the members. This can be translated into recommended practices such as communication, attention to other's interests, ideas proposal and development, sharing points of views.

Areas in which there are most of the conflicts are:

- Project priorities,

- Management procedures of the group,

- New members implantation,

- Costs,

- Planning,

- Members' personality,

- Deadlines.

To reduce conflicts and manage better the members it is important to create a social environment without stress - or trying to reduce it to the minimum -one way of doing so can be entertainment. The entertainment must not be undervalued, it represents the first barrier against stress and consequently conflicts.

Working in a team is seen as something positive, although, it hides difficulties and crises that besides the conflicts a team must face. 
Many teams fail and where those teams fail one succeeds. Usually, frustration is the reason why members leave the team, and most of the time frustration is caused by bad management.

Typical mistakes made by managers emerge when:

- When the team cannot overtake poor management plans;

- The work environment is hostile, and it presents a strong hierarchical structure of command;

- The team lacks communication;

- The training is poorly performed, and the personnel selection is inadequate.

Moreover, a common mistake is to consider teamwork as something that can easily tackle any issues, overloading the members with multiple tasks and missions to complete, with unrealistic expectations. For a successful team three basic ingredients are necessary:

- Cooperativity,

- Trust,

- Cohesion.

For this reason, it is important to build the "dream team" and when not available, members of the team must be well-synchronised with each other.

Therefore, we introduce the team building process, which defines the process of training and learning through the use of methods and multidisciplinary teaching aimed at improving cooperation, communication and lowers conflicts.

The team building scope is to obtain from the team the best performance, to do so, simulations are performed, and analysis are then discussed to identify the main issues.

We then propose based on papers review a few characteristics that a team should have to have high performance:

- Participative leadership,

- Shared responsibility,

- Strong communication skills,

- Goal-driven,

- Creativity,

- Nimbleness.

To perform the best, managers must include team-building sessions in their training process (Mollo et al., 2005). By the years the leaderships shifted from the leader instructing the single individual to instruct the group as a whole.

It was then coined the expression "group leadership", it was created after the necessity to distinguish "leading a group" and "leading people". Dynamics are quite different and for this reason, express a different concept was necessary since also the dynamics within the group boundaries are different. The leadership is different.

Leadership is the guiding role in the team, the leader manages the other individuals - led or followers - inspiring them to trust and instructing them towards the goal. Holding the leadership role is not an easy task. It means leading the followers through a journey in which not only one approach is valid. The leader must be able to detect and understand whether to 
apply one leadership style or the other, how to modulate it and how to adjust one specific style to the situation.

\section{f. Leadership}

In the previous sections, it has been extensively explained how effective teambuilding can remarkably improve the team's performances.

Applying an effective, versatile, flexible and understanding leadership can enlarge the scope of the group and ease the dynamics within the organisation itself.

The use of proper leadership is not optional. It is needed in a team; it is an organisational requirement and one of the fundamental yet effective forms of social control over the members. Leadership is defined as a process through which a subject influences a group of individuals in order to reach a common goal (Running et al., 1999), therefore, during this process, the leader influences his/her collaborators to pursue voluntarily pre-set objectives.

This takes into account some aspects:

- It is a process between leader and followers,

- It is strictly bonded to social influences,

- It is manifested throughout a different level of the organization,

- It revolves around the goal achievement.

However, it is difficult to simply define leadership with these four aspects and a few words as a conceptual definition. Leadership is something very broad. It was the beginning of the past century academics started to make research in the field of management. The researchers were mostly focused on defining the peculiar traits of the leader. In the 1950s and 1960s, more careful and in-depth studies on leadership styles were tackled. Finally, in the 1960s and 1970s, finding it difficult to analyse and precisely define specific leadership styles, academics focused on contingent studies, aiming at identifying the most effective leadership behaviours.

Nonetheless, it is important to properly distinguish between management and leadership, these two concepts do not overlap. In fact, managers handle situations and leaders guide the situation and the two activities are not synonyms (Mollo et al., 2005). In general, management involves functions related to planning, whilst leaders inspire the members and find the motivation to pursue the plan designed by the management.

Tracing back the first study about leadership, the theory of traits defines the "trait" of a leader as the characteristics physical or of the personality that can be developed by training or with experience (Rosenbach \& Robert J., 2018). Furthermore, we define the traits of "bad leadership":

- Incompetence,

- Lack of nimbleness,

- Insensible,

- Narrowminded,

- Malice.

We now introduce the leadership styles that are effective in influencing the followers. Firstly, contingency leadership in which the efficacy of a particular style can be adjusted according to the situation, there are not universal valuable styles that fit any situation. Situational control 
and control over the relationships between members of the group is fundamental when it comes to a "good leader". A leader in order to have good situational control should master the following three variables(Tuckman, 1965):

- Relationships between leader and followers;

- Clarity in roles;

- Who has the authority.

Usually, different styles of leadership are the outcome of the fusion of different styles, using authority and involving the members.

Leadership approaches:

- Full range, in this approach the leadership can vary a lot from a laissez-faire approach to a transitional leadership and even transformational leadership;

- Laissez-faire, it is intended those behaviours that let the members of the group take responsibility, providing precise indications but leaving the individuals to process the information and act consequently;

- Transitional leadership, it is based on rewards and penalties in order to promote motivation and performance;

- Transformational leadership, it is the kind of leadership with more involvement of the members with trust, loyalty and effort between all the levels of the organisation. The transformational leader is very intelligent, and they can inspire, give attention to the single entity, and stimulate intellectually each member of the group.

- Leader-collaborator exchange, it is an approach based on a quality- relationship between leader and follower. There are different grades within the group, and they are treated differently according to the relationship built with the leader.

- Servant leadership, it was theorised in the 1970s. the idea was that when a leader has a position of service towards his/her collaborators, taking care of their needs before of his/her. A servant leader is capable of empowerment, hence, to work on himself/herself in order to make the others work better. This type of leadership involves understanding, listening and working together as a very interwoven team.

Various studies have proved that followers respect more leaders that promote respect and have some sort of empathy towards the team.

\section{Emotional intelligence}

A respectful leader must have in his/her skillset emotional intelligence. A leader that is firstly able to control himself/herself and then the other can provide a shared and mutual respect in the group and the organisation. For emotional intelligence is intended the ability to manage relationships in order to ease the process of goal achievement.

\section{Resilience}

Resilience is another capability that is defined as the ability to adapt positively to different contexts and facing disruptions, to find solutions and design plans that are then put into practice successfully.

\section{Empathy}

The capacity to detect and analyse the mood of the group members, establishing a connection with the other person. It is developed by actively listening. 


\section{CONCLUSIONS AND SUGGESTIONS FOR FUTURE RESEARCH}

To conclude, situational leadership is not easy to achieve, nonetheless, it is a mixture of different types of leadership since there is not one unique valid style.

After we discussed what a group is and how it is created, what are the characteristics of a group and what are the roles of the leader within the organisational structure, we can conclude and provide suggestions for future research.

The success of a leader is strictly related to personal skills which are possible to develop mostly the leader is born with those skills, he/she just need to develop more- managing the group.

Thus, we can state that in the organizations management of a business, a fundamental role is played by the "leadership style", from the most authoritarian to the most participative, since administrating the working relationships in complex organizations, influence their final results.

In fact, within an organization, the leadership has, as demonstrated, therefore the function of uniting the needs of the individual to the needs of the group and vice versa, to achieve the final objective of the organizational mission. The leadership approach does not presume a unique approach to every situation, but it must be calibrated in time and space, taking into account interpersonal relationships, the internal environment, the external environment, the personality of the members, their attitudes, etc.

The person or those who hold the leadership, but also the organization itself, must in fact be able to know and understand how and when to modulate their managerial style to achieve the desired results, always bearing in mind that leadership is a complex phenomenon and that the behavior of its members, therefore, depends very much on the leadership attitude that guides them.

We focused on the leader features and leadership styles, future research can focus on the inner structure of an organisation or what the forces are within an organization.

\section{REFERENCES}

De Andreis F., Lo stile di leadership nella direzione d'impresa, Youcanprint, Lecce, 2017

Mollo, S. M., Stanz, K., \&amp; Groenewald, T. (2005). Leadership Competencies In A Manufacturing Environment. SA Journal of Human Resource Management, 3(2), 34-42. https://doi.org/10.4102/sajhrm.v3i1.56

Rosenbach, W. E., \&amp; Robert J., A. (2018). Bad Leaders. Contemporary Issues in Leadership, 215-223. https://doi.org/10.4324/9780429494000-24

Running, D. M., Ligon, J. B., \&amp; Miskioglu, I. (1999). Leadership, Theory and practice. Journal of Composite Materials, 33(10), 928-940.

Spencer, K. L. (1993). The Wisdom of Teams: Creating the High-Performance Organization. Academy of Management Perspectives, 7(3), 100-102. https://doi.org/10.5465/ame.1993.9411302368

Tuckman, B. W. (1965). Developmental sequence in small groups. Psychological Bulletin, 63(6), 384-399. https://doi.org/10.1037/h0022100 